\title{
PROPOSTA DE CRIAÇÃO DA APRM - ÁREA DE PROTEÇÃO E RECUPERAÇÃO DE MANANCIAL DO ALTO CURSO DA BACIA DO RIO SANTO ANASTÁCIO
}

\author{
Erica Aparecida Fernandes da Mota ${ }^{1}$ \\ Maria Helena Pereira ${ }^{2}$
}

\begin{abstract}
RESUMO
Na região do Oeste paulista se insere a Bacia Hidrográfica do Rio Santo Anastácio, cujo manancial de maior relevância possui mesmo nome, sendo que a principal cidade nela inserida Presidente Prudente, o utiliza para suprir parte da demanda do abastecimento público de água. O seu destaque regional perante as demais cidades, desde sua origem, é a agropecuária que, ao transcorrer do tempo, provocou aumento significativo da população, além da instalação de algumas indústrias. Até os dias atuais se encontra em constante expansão urbana, de forma que as diretrizes do Plano Diretor municipal preveem um aumento da malha urbana até às margens do Rio Santo Anastácio, fato já constatado recentemente com pressão do setor imobiliário, resultando, consequentemente, impactos ambientais negativos sobre os recursos naturais, em particular, diretamente na disponibilidade hídrica. É nesse sentido que surge a proposta de criação de área a ser legalmente protegida por lei específica como, no caso, Área de Proteção e Recuperação de Manancial, como base jurídica para o planejamento ambiental, com a pretensão de mitigar efeitos negativos gerados por esse processo de crescimento urbano acelerado. Esta é o alvo principal deste estudo. Para tal, aqui fica adotado o conceito de bacia hidrográfica como unidade de gestão, ferramenta essencial na realização de um gerenciamento integrado dos recursos hídricos que deve contar com o auxilio da ação participativa do Comitê de Bacias Hidrográficas. Analisar-se-á, portanto, como esses elementos serão significativos na resolução de problemas ambientais de modo a minimizar conflitos sociais gerados pelo direito ao uso da água.
\end{abstract}

PALAVRAS-CHAVE: Gerenciamento, Planejamento Ambiental, Recursos Hídricos.

\section{PROPOSED CREATION APRM - PROTECTION AREA AND HIGH OF STOCK RECOVERY RIVER BASIN COURSE SANTO ANASTÁCIO}

\begin{abstract}
In the western region of São Paulo state inserts the Santo Anastácio River Basin, whose most relevant source has the same name, and the main city it inserted Presidente Prudente, use it to supply part of the demand of the public water. Your regional prominence towards other cities, from its origin, it is agriculture that in course of time, caused a significant increase in population, as well as installing some industries. To the present day is constantly urban expansion, so the guidelines of the Municipal Director Plan predict an increase in urban area to the banks of the Santo Anastácio River, a fact already recently observed with pressure from real estate, resulting hence environmental impacts negative on natural resources, in particular, directly on water availability. That is why there is the area
\end{abstract}

\footnotetext{
${ }_{1}^{1}$ Graduanda em Engenharia Ambiental, UNOESTE. E-mail: erica.fmota@hotmail.com

2 Doutora, UNOESTE. E-mail: madelainy1361@hotmail.com
} 


\title{
Periódica Eletrânica

of creating proposal to be legally protected by specific law as in the case Protection Area and Fountains Recovery, as the legal basis for environmental planning, with the intention of mitigating negative effects generated by this process accelerated urban growth. This is the main target of this study. To that end, here's adopted the concept of watershed as a management unit, an essential tool in the implementation of an integrated management of water resources which must rely on the help of participatory action of the Watershed Committee. Analyze It will, therefore, how these elements will be significant in the resolution of environmental problems in order to minimize social conflicts generated by the right to use the water.

KEYWORDS: Management, Environmental Planning, Water Resources.

\section{PROPUESTA DE CREACIÓN APRM - PROTECCIÓN ÁREA Y ALTA DE STOCK DE RECUPERACIÓN CUENCA DEL RÍO CURSO SANTO ANASTÁCIO}

\begin{abstract}
RESUMEN
En la región del oeste de São Paulo se ajusta a la cuenca del río Santo Anastácio, cuya fuente más relevante tiene el mismo nombre, y la ciudad principal se inserta Presidente Prudente, lo utilizan para cubrir parte de la demanda del servicio publico. Su prominencia regional hacia otras ciudades, desde su origen, es la agricultura, que en el transcurso del tiempo, provocó un aumento significativo de la población, así como la instalación de algunas industrias. Para el día de hoy es la expansión urbana constante, por lo que las directrices de la Plano Director Municipal predicen un aumento del área urbana a las orillas del río Santo Anastácio, un hecho ya observado recientemente con la presión de los bienes raíces, lo que resulta, por tanto, los impactos ambientales negativos sobre los recursos naturales, en particular, directamente en la disponibilidad de agua. Es por eso que es el área de la creación de propuesta para ser jurídicamente protegido por la ley específica como en el caso de la zona de protección y de la recuperación de fuentes, como la base jurídica para la planificación del medio ambiente, con la intención de mitigar los efectos negativos generados por este proceso acelerado de crecimiento urbano. Este es el objetivo principal de este estudio. Con ese fin, aquí está adoptado el concepto de cuenca hidrográfica como unidad de gestión, una herramienta esencial en la aplicación de una gestión integrada de los recursos hídricos que debe confiar en la ayuda de la acción participativa del Comité de Cuenca. Analizar Será, por lo tanto, cómo estos elementos serán significativos en la resolución de los problemas ambientales con el fin de minimizar los conflictos sociales generados por el derecho de uso del agua.
\end{abstract}

PALABRAS CLAVE: Gestión, Planificación del Medio Ambiente, Recursos Hídricos. 


\title{
Periádica Eletranica

\section{INTRODUÇÃO}

Entre todos os recursos naturais disponíveis e explorados pelo homem a água é considerada o mais essencial deles, sendo esta indispensável para o suprimento de necessidades básicas de sobrevivência das espécies animais e vegetais; assim pensando, dever-se-ia, também, ser o mais preservado.

De acordo com Braga et.al. (2005), a água está presente em 70\% da superfície de todo o planeta, porém, o que devemos observar é a sua disponibilidade, sendo que apenas 0,5\% representam a água doce possível de exploração. Ainda assim, a água deve apresentar certas características físicas, químicas e biológicas preservadas, para que possamos ter a viabilidade de sua utilização, de forma que não basta ter quantidade, esse fator deve estar atrelado à qualidade.

Ribeiro (2003, p. 73) afirma que "A distribuição natural da água pelo mundo não coincide com a ocupação humana, gerando pontos de tensão e luta por água doce".

Assim, Braga et. al, 2005 cita que:

Existem regiões no planeta com intensa demanda de água, tais como os grandes centros urbanos, os polos industriais e as zonas de irrigação. Essa demanda pode superar a oferta de água, seja em termos quantitativos, seja porque a qualidade da água local esta prejudicada em virtude da poluição. Tal degradação da sua qualidade pode afetar a oferta de água e também gerar graves problemas de desequilíbrio ambiental. (p. 77)

Complementando essa ideia Berbet (2003, p.81) diz:

\begin{abstract}
Educação, saúde, saneamento, transporte, criminalidade, terrorismo e narcotráfico certamente continuaram sendo grandes desafios a vencer, mas produção de alimentos, geração de energia limpa, moradias, criação de novos empregos e água serão, certamente os maiores. Destes, a água será - maior de todos, menos por seu volume e mais por sua distribuição irregular na face da Terra, acrescida de seu desperdício, poluição e degradação de mananciais e reservatórios naturais.
\end{abstract}

Para Ribeiro (2003), os números indicadores da falta de água no mundo são bem expressivos e essa situação pode gerar conflitos quanto ao seu uso. O autor enfoca ainda, o nosso modo de vida baseado no consumo exacerbado como o fator primordial e potencial para a crise que se instala; é preciso que repensemos nisso para podermos então alcançar o gerenciamento adequado dos recursos hídricos. 


\section{Periádica Eletranica

Difícil imaginar o que seria de todos nós sem acesso à água para a execução de simples tarefas em nosso dia-a-dia, pois ela se faz indispensável para nossa sobrevivência. Nesse sentido, Mota (2010), afirma que dessa forma necessário se faz o manejo adequado desse precioso recurso utilizado de maneira racional para as mais diversas finalidades, o autor salienta ainda que "Este é um dos grandes desafios da humanidade: saber aproveitar seus recursos hídricos, de forma a garantir os múltiplos usos, hoje e sempre". (p.137).

Assim, surge o desenvolvimento sustentável. Salati, Lemos e Salati (2006), traz-nos a observação da fácil percepção do fato das principais civilizações terem-se desenvolvido com mais sucesso em regiões onde era possível a ocorrência de disponibilidade hídrica.

De acordo com Tundisi (2005), a qualidade e quantidade de água estão diretamente ligadas ao crescimento populacional e ao desenvolvimento, trazendo como conseqüência maior demanda por esse recurso, gerando conflitos fatores esses que também implicam em questões de saúde pública, com o manejo indevido deste bem humanitário, podendo ocasionar doenças. Assim, percebemos um aumento quanto à noção da limitação da água, visto que mesmo podendo ser recuperada por processos caros muitas vezes a degradação ambiental é tamanha que inviabiliza a recuperação da mesma.

Segundo Mota (2010) ao longo da evolução durante o processo de desenvolvimento as populações não se atentaram aos devidos cuidados a serem tomados com a natureza, uma vez que essa era vista como algo a ser submetido às necessidades humanas, sem que a mesma precisasse ser explorada, levando em consideração suas limitações. A situação atual de nossos rios deixa isso muito bem evidenciado, principalmente quanto ao processo de urbanização acelerado como com a ocupação de terrenos irregulares em áreas de preservação permanente, desmatamento dessas áreas, despejo clandestinos de esgoto domestico e efluentes industriais.

\footnotetext{
Um dos principais impactos produzidos no ciclo hidrológico é a rápida taxa de urbanização, com inúmeros efeitos diretos e indiretos. Essa urbanização tem grandes consequências, alterando substancialmente a drenagem e produzindo problemas à saúde humana, além de impactos como enchentes, deslizamentos e desastres provocados pelo desequilíbrio no escoamento das águas (Tundisi, 2005, p.41).
} 


\section{Periádica Eletranica

Temos o processo de degradação ambiental também acentuado nas áreas rurais, de acordo com Lima e Silva, Guerra e Dutra (2010), nesse meio muitas vezes a degradação ambiental chegam a tal ponto em que seu custo torna-se muito alto inviabilizando o processo de recuperação, o que leva a vários fatores prejudiciais aos recursos hídricos, tais como, poluição por defensivos agrícolas, assoreamento por carregamento de sedimentos oriundos dos processos erosivos que se intensificam.

Tundisi (2005, p. 88 e 89) cita ainda que:

O desenvolvimento agrícola depende da disponibilidade de água e de seu uso adequado. Alem da água para a irrigação, o uso para abastecimento rural representa desafio relevante, pois nessa área estão concentrados, muitos problemas de saúde pública relacionado ao abastecimento e ao saneamento (Tundisi, 2005, p.88 e 89).

Tundisi (2005), ainda comenta sobre os usos múltiplos da água que é variado conforme as características de cada região, isso pressiona a demanda desse recurso seja superficial ou subterrâneo. Essa diversidade quanto às múltiplas utilizações inclui o uso doméstico, irrigação, industrial, navegação, recreação e turismo, pesca, hidrelétrico e mineração, resultando numa gama maior de impactos causados.

Para um melhor gerenciamento deste recurso é empregado o conceito de Bacia Hidrográfica, sendo considerada como unidade de gestão alvo de um planejamento ambiental no âmbito do desenvolvimento sustentável. (PIRES; SANTOS E DEL PRETTE, 2002, p.21).

De acordo com Dibieso (2013) a Bacia Hidrográfica vem a ser um instrumento básico na gestão de recursos hídricos, uma vez que esta abrange elementos simultâneos como constituição litológica, características do relevo e solo, processo de industrialização, desenvolvimento agropecuário, fauna, flora, taxa de urbanização entra outros fatores que constantemente se interrelacionam.

De acordo com Mota (2010), a Bacia Hidrográfica pode ser entendida como a área geograficamente drenada pelas águas de um rio principal que recebe contribuição das águas dos seus afluentes, sendo uma área delimitada composta por recursos naturais que interagem entre si, de modo que se deve buscar um equilíbrio entre eles. 


\title{
Periádica Eletranica

Boim et al. (2009) salienta que dentre todos os recursos naturais provenientes da unidade hidrográfica a água é tida o de maior importância, sendo que a manutenção de suas características com considerável padrão de qualidade se relaciona com os diversos usos aos quais ela se destinada, com destaque para o abastecimento humano que exige uma boa manutenção do manancial de abastecimento que deve ser preservado ao máximo e poupado das degradações antrópicas, garantindo assim, sua a produtividade e qualidade.

Pires; Santos e Del Prette (2002) expõem a interpretação mais ampla do termo Bacia Hidrográfica, que vem a ser um importante instrumento usado na unidade de gestão da paisagem em se tratando de planejamento ambiental, essa perspectiva agrega metas na busca de um desenvolvimento sustentável embasado em três pilares principais: o desenvolvimento econômico; igualdade social, econômica e ambiental; e a sustentabilidade. Esses objetivos devem ser traçados em conjunto numa visão em longo prazo, os quais afirmam que:

\begin{abstract}
A adoção do conceito de Bacia Hidrográfica para a conservação de recursos naturais esta relacionada à possibilidade de avaliar, em uma determinada área geográfica, o seu potencial de desenvolvimento e a sua produtividade biológica, determinando as melhores formas de aproveitamento dos mesmos, com o mínimo de impacto ambiental. (p.21)
\end{abstract}

Assim, os autores complementam que se faz necessário o conhecimento de toda essa área, levantando aspectos referentes à sua constituição e constante transformação para que se possa propor um planejamento que não seja temporário e traga medidas de eficácia.

Surge então conforme Tundisi (2005 apud Rosengrant, 1996; Rosengrantet al., 1994-1995), o modelo de gerenciamento integrado como ferramenta do planejamento ambiental a ser utilizado na gestão de bacias hidrográficas com uma perspectiva a longo prazo. Esse planejar deve envolver a participação dos múltiplos usuários tendo representatividade de autoridades, organizações nos âmbitos público e privado, meio acadêmico e a população como um todo, possibilitado a resolução de conflitos.

Complementando a ideia apresentada Pires; Santos; Del Prette (2002) ressaltam o gerenciamento dos recursos naturais de modo integrado como instrumento eficiente na resolução de problemas ambientais, vindo a ser um exercício de extrema importância, o qual deve se embasar na consideração de que 


\section{Periódica Eletranica

os recursos disponíveis na bacia hidrográfica são de bem comum a toda sociedade. Por essa razão, a mesma deve estar ciente e conscientizada quanto às questões ambientais envolvidas em determinada unidade de estudo.

Sendo assim, Capri Junior e Leal (2012) afirmam que as composições dos Comitês de Bacias facilitam a disseminação do conhecimento e atividades que integram as diferentes representatividades da sociedade civil, possibilitando que esses atuem dentro desse comitê na tomada de decisões e no planejamento gerencial dos recursos.

Esse trabalho relatará a situação da Bacia Hidrográfica do Alto Curso do Rio Santo Anastácio, de grande relevância para a região, localizada na Unidade de Gerenciamento de Recursos Hídricos do Pontal do Paranapanema - UGRHI- 22, no Oeste Paulista; com área total de 19.830,00 ha a Bacia, abrange parte dos municípios de Presidente Prudente, Pirapozinho, Regente Feijó, Anhumas e Álvares Machado. Interceptada pelas rodovias Assis Chateubriand, Raposo Tavares, e Júlio Budiski.

Possui manancial usado para fins de abastecimento público e, ainda assim, têm em sua bacia inúmeros problemas ambientais, como erosões, rios assoreados, desmatamento e ocupação das suas áreas de preservação permanente, tanto por pastagem, quanto pela expansão urbana, oferecendo forte risco ambiental que já compromete a capacidade dos seus rios e manancial.

De acordo com Boim et. al. (2009, apud CPTI, 1999), o processo de ocupação da região se caracteriza pela prática da agricultura e pecuária de maneira intensa, que ocasionou problemas ambientais, fazendo com que a região fosse amplamente desmatada, até mesmo nas áreas de preservação permanente; esse fator combinado com as características morfológicas locais provocou surgimento de inúmeros processos erosivos e refletiu no assoreamento de corpos d'água, associado ao manejo indevido do solo fazendo com que o mesmo perdesse parte de sua fertilidade. As consequências sofridas nessa bacia durante sua ocupação exigem a tomada medidas de recuperação e planejamento integrado a fim de reverter essa degradação.

Desta maneira se faz necessária a implantação de um planejamento adequado a fim de solucionar essas questões. Será discutida no decorrer desse 


\section{Periódica Eletranica

estudo a proposta da criação da APRM - Área de Proteção e Recuperação de Manancial do Alto Curso do Rio Santo Anastácio.

Para a escolha da bacia de estudo uma condição relevante foi a preocupação com desenvolvimento de ações que reflitam na recuperação e proteção dos mananciais que compõem essa unidade hidrográfica. Em atenção ao rio que dá nome a bacia, o Santo Anastácio, que abastece o principal centro urbano regional da URGHI-22, o Município de Presidente Prudente - SP.

Tendo como principal embasamento jurídico a Lei Federal $n^{\circ}$ 9.443/97 conhecida como Lei das Águas que institui a Política Nacional de Recursos Hídricos e criou o Sistema Nacional de Gerenciamento de Recursos Hídricos.

Serão ainda usadas como embase as Leis Estaduais n $7.663 / 91$ que cria o Sistema Integrado de Gerenciamento de Recursos Hídricos - SIGRH e a de $n^{\circ}$ 9.866/97, que estabelece diretrizes e normas para a proteção e recuperação da qualidade ambiental das bacias hidrográficas de interesse regional para 0 abastecimento das populações atuais e futuras do Estado de São Paulo. Esta última faz a seguinte consideração, "os mananciais representam as águas subterrâneas, superficiais fluentes, emergentes ou em depósito, efetiva ou potencialmente utilizáveis para o abastecimento público (São Paulo, 1997)".

Garcia e Valencio (2003, p.190) enfatizam que:

O SIGRH foi estruturado de forma a possibilitar o estabelecimento de eficiente rede de gerenciamento das águas no Estado de São Paulo, sendo disposto da seguinte forma:

1. Com estruturas deliberativas: Conselho Estadual de Recursos Hídricos $(\mathrm{CRH})$ e Comitês de Bacias Hidrográficas (CBHs).

2. Com estrutura técnica: Comitê Coordenador da Política Estadual de Recursos Hídricos (CORHI).

3. Com estrutura financeira: Fundo Estadual de Recursos Hídricos (FEHIDRO).

Dessa forma, Garcia e Valencio (2003) salientam que "o CRH é um colegiado central, consultivo, normativo e deliberativo, responsável pela formulação, pela implantação e pelo acompanhamento da Política Estadual de Recursos Hídricos (p.190)", e ainda rege as diretrizes gerais do Plano Estadual de Recursos Hídricos que, por sua vez, serve de base para que os Comitês de Bacias, como colegiados a níveis regionais, possam definir as prioridades de planejamento no 


\section{Periódica Eletranica

gerenciamento da bacia que tem por recomendação a ocorrência de modo integrado. "A formação dos comitês de bacias hidrográficas representou grande avanço político-institucional para a gestão das águas, respeitando a paridade de votos entre o Estado, os municípios e a sociedade civil (p.190)."

Mauad e Lima (2003) dizem que todas as decisões tomadas no gerenciamento de recursos hídricos envolvem diversos fatores; essas ações devem ser consentidas com a participação de vários segmentos da sociedade, o que vem a ser uma tarefa complexa objetivando melhorias rumo ao desenvolvimento sustentável por meio de planejamento estratégico. Ribeiro (2003, p.73) completa ainda que "é fundamental que se criem normas para a regulação ao acesso e ao uso dos recursos hídricos".

TEMA: Proposta de criação da APRM - Área de Proteção e Recuperação de Manancial do Alto Curso da Bacia do Rio Santo Anastácio.

\section{OBJETIVOS}

\section{Geral}

Discutir a proposta de criação da Área de Proteção e Recuperação de Mananciais - APRM no Alto Curso do Rio Santo Anastácio por meio do Plano de Desenvolvimento e Proteção Ambiental - PDPA.

\section{Específicos}

- Discutir o gerenciamento da Bacia do Alto Curso do Rio Santo Anastácio;

- estudar as medidas tomadas e resultados alcançados;

- apresentar projeção de cenário futuro.

\section{METODOLOGIA}

Por meio de levantamento bibliográfico, artigos eletrônicos, periódicos, dissertações, teses, dentre outros. Coleta de dados em órgãos oficiais, IBGE, INPE, DAEE, CETESB, Comitê de Bacias Hidrográficas do Pontal do Paranapanema, uso de mapas elaborados, apontado as características peculiares da área a ser estudada, na busca de melhor compreensão da situação em que se encontra o gerenciamento na Bacia Hidrográfica do Alto Curso do Rio Santo Anastácio. 


\section{Periódica Eletrânica

Serão apontados, também, aspectos geológicos, geomorfológicos, climáticos, hidrológico, uso e ocupação do solo, hidrologia e cobertura vegetal para apontarmos sugestões de melhores formas de utilização dos recursos naturais sem que haja o seu comprometimento.

Dessa forma será discutida a proposta de criação da Área de Proteção e Recuperação de Mananciais - APRM no Alto Curso do Rio Santo Anastácio por meio do Plano de Desenvolvimento e Proteção Ambiental - PDPA, já elaborado pela Universidade Estadual Paulista "Júlio de Mesquita Filho" -UNESP, Campus de Presidente Prudente.

\section{RESULTADOS A SEREM ALCANÇADOS}

A presente pesquisa em andamento far-se-á relevante por discutir junto à comunidade acadêmica e cientifica da área da engenharia ambiental, e outras afins, a proposta de criação da APRM do Alto Curso do Rio Santo Anastácio como instrumento de gerenciamento desse importante recurso hídrico regional tendo em vista seu aproveitamento para abastecimento público.

Tratar-se-á de instrumento fundamental na proposição de criação da lei que visará à integração e participação dos diferentes usuários em comum de tal recurso hídrico, por meio do Comitê de Bacia Hidrográfica constituído de diversas esferas de organizações sociais, tanto pública quanto privada.

O desenvolvimento desse trabalho abordará, inclusive, problemas em diferentes escalas no contexto atual; bem como, fará uma projeção para cenários futuros, como forma de propor soluções para minimização de conflitos sociais pelo uso deste recurso vital.

\section{CONCLUSÃO}

A proposta de criação da APRM em andamento será acompanhada e discutida no presente estudo, por tratar-se de instrumento vital para a preservação dos recursos hídricos, constantemente degradado pela ação antrópica intensiva, associada à expansão urbana dos municípios localizados no entorno da bacia. 


\section{Periódica Eletrânica \\ Fórum Ambiental}

da Alta Paulista
Volume 11, Número 06, 2015

Planejamento e Gestão dos Recursos Hídricos

Trata-se, portanto, de uma pesquisa que apresentará resultados conclusivos, que poderão subsidiar as discussões de propositura de uma lei estadual que proporá gerenciamento integrado e sustentável dos recursos hídricos do Alto Curso da Bacia do Rio Santo Anastácio.

Trata-se de legislação especifica que visará tutelar a disponibilidade hídrica garantindo a sustentabilidade e uso aos diversos usuários, de modo que esta seja fundamento legal para a resolução dos conflitos resultantes dos múltiplos usos dos recursos hídricos.

\section{REFERENCIAS}

BERBET, Carlos Oití O. O Desafio das Águas. In: MARTINS, Rodrigo Constante; VALENCIO, Norma Felicidade Lopes da Silva. Uso e Gestão dos Recursos Hídricos no Brasil: Desafios Teóricos e Politico-institucionais. São Carlos; RiMa; 2003. p.81- 97.

BRAGA, Benedito. et. Al. Introdução á Engenharia Ambiental: O Desafio do Desenvolvimento Sustentavel. São Paulo: Pearson Prentice Hall, 2005.

BRASIL. Lei n 9.433, de 08 de janeiro de 1997. Institui a política nacional de recursos hídricos, cria o sistema nacional de gerenciamento de recursos hídricos. Legislação Sobre Recursos Hídricos. Comitê de Bacia Hidrográfica do Pontal do Paranapanema.

BOIN, Marcos Norberto et al. Projeto de Recuperação das Áreas de Preservação Permanente na Bacia Hidrográfica do Manancial do Alto Curso do Rio Santo Anastácio/SP. XVIII Simpósio Brasileiro de Recursos Hídricos, 2009, Campo Grande. Anais do XVIII Simpósio Brasileiro de Recursos Hídricos, 2009.2 Disponível em: <http://www.abrh.org.br/sgcv3/UserFiles/Sumarios/c42ab701b2e4c30a3001d95949012208_8e4213ce e38370d5056bef20ac6e1e26.pdf > Acesso em: 02 mar. 2015.

CAPRI JUNIOR, Salvador; LEAL, Antônio Cesar. Mapeamento de Riscos Ambientais e Planejamento Participativo no Manancial Rio Santo Anastácio - UGRHI do Pontal do Paranapanema - São Paulo. Revista Geonorte, Edição Especial, V.3, N.4, p.1069-1081, 2002. Disponível em: <http://www.revistageonorte.ufam.edu.br/attachments/009_MAPEAMENTO\%20DE\%20RISCOS\%20A MBIENTAIS\%20E\%20PLANEJAMENTO\%20PARTICIPATIVO\%20NO\%20\%20MANANCIAL\%20RIO \%20SANTO\%20ANAST\%C3\%81CIO\%20\%E2\%80\%93\%20UGRHI\%20PONTAL\%20DO\%20PARAN APANEMA\%20-\%20S\%C3\%83O\%20PAULO\%202.pdf > Acesso em: 02 mar. 2015.

DIBIESO, Eduardo Pizzolim. Planejamento Ambiental e Gestão dos Recursos Hídricos: Estudo Aplicado a Bacia Hidrográfica do Manancial do Alto Curso do Rio Santo Anastácio/SP. Presidente Prudente: [s.n.], 2013.xviii, 283 f.: il. Tese (doutorado) - Universidade Estadual Paulista, Faculdade de Ciências e Tecnologia. Disponível em: <http://hdl.handle.net/11449/105072> Acesso em: 02 mar. 2015.> Acesso em: 02 mar. 2015.

GARCIA, Argentina Carlota Moreira do Carmo; VALENCIO, Norma Felicidade Lopes da Silva. Gestão de Recursos Hídricos no Estado de São Paulo: Obstáculos Técnicos e Políticos a sustentabilidade das Praticas Decisórias em Comitês de Bacias. Água Doce: Conflitos e Segurança Ambiental. In: MARTINS, Rodrigo Constante; VALENCIO, Norma Felicidade Lopes da Silva. Uso e Gestão dos Recursos Hídricos no Brasil: Desafios Teóricos e Politicoinstitucionais. São Carlos; RiMa; 2003. p.187-202.

LIMA E SILVA, Pedro Paulo; GUERRA, Antônio José Teixeira; DUTRA, Luiz Eduardo Duque. E. D.; Subsídio Para Avaliação Econômica de Impactos Ambientais. In: CUNHA, Sandra Batista; 


\section{Periódica Eletranica

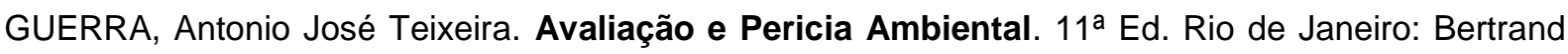
Brasil, 2010. 286p.

MAUAD, Frederico Fabio; LIMA, Guilherme de. Planejamento Estratégico de Sistemas Hídricos. In: MARTINS, Rodrigo Constante; VALENCIO, Norma Felicidade Lopes da Silva. Uso e Gestão dos Recursos Hídricos no Brasil: Desafios Teóricos e Politico-institucionais. São Carlos; RiMa; 2003. p.99- 126.

MOTA, Seutônio. Introdução a Engenharia Ambiental. 4ed. Rio de Janeiro: Expressão Gráfica; 2010.

RIBEIRO, Wagner Costa. Água Doce: Conflitos e Segurança Ambiental. In: MARTINS, Rodrigo Constante; VALENCIO, Norma Felicidade Lopes da Silva. Uso e Gestão dos Recursos Hídricos no Brasil: Desafios Teóricos e Politico-institucionais. São Carlos; RiMa; 2003. p.71-77.

SÃO PAULO (Estado). Lei n. 7.663/91, de 30 de dezembro de 1991. Institui a Política Estadual de Recursos Hídricos e o Sistema Integrado de Gerenciamento de Recursos Hídricos. Legislação Sobre Recursos Hídricos. Comitê de Bacia Hidrográfica do Pontal do Paranapanema.

SÃO PAULO (Estado). Lei n. 9.866, de 28 de janeiro de 1997. Dispõe sobre diretrizes e normas para a proteção e recuperação das bacias hidrográficas dos mananciais de interesse regional do Estado de São Paulo e dá outras providencias. Disponível em: <http://www.al.sp.gov.br/repositorio/legislacao/lei/1997/lei-9866-28.11.1997.html>. Acesso em: 09 mar. 2015.

PIRES, José Salatiel Rodrigues; SANTOS, José Eduardo; DEL PRETTE, Marcos Estevan. A Utilização do Conceito de Bacia Hidrográfica para a Conservação dos Recursos Naturais. In: SHIAVATTI, Alexandre; CAMARGO, Antonio Fernando Monteiro. Conceitos de Bacias Hidrográficas: Teorias e Aplicações. Ilhéus, 2002.

TUNDISI, José Galizia. Água no Século XXI: Enfrentando a Escassez. São Carlos: RiMa, IIE, 2. ed., 2005. 